\title{
Delayed Recrudescence to Toxic Salicylate Concentrations After Salsalate Overdose
}

\author{
Patrick L. West • B. Zane Horowitz
}

Published online: 20 April 2010

(C) American College of Medical Toxicology 2010

\begin{abstract}
Salicylates are common exposures. We report an unusual case of salicylate ingestion, as salsalate, with resolution of symptoms and return of salicylate levels to non-toxic values, with a subsequent, unexpected recrudescence to toxic levels requiring reinstitution of therapy. A 31-year-old man ingested unknown amounts of salsalate, hydroxyzine, and a benzodiazepine. He was intubated and treated with IV sodium bicarbonate and two doses of oral activated charcoal. Eight hours after presentation, his serum salicylate concentration peaked at $55 \mathrm{mg} / \mathrm{dL}$, and then decreased to a nadir of $5.6 \mathrm{mg} / \mathrm{dL} 38 \mathrm{~h}$ after presentation, coinciding with return of GI motility. Several hours later salicylate concentrations began to rise, peaking $67 \mathrm{~h}$ after presentation at $61.7 \mathrm{mg} / \mathrm{dL}$. He was treated with sodium bicarbonate and charcoal, which resulted in decreased serum salicylate to therapeutic levels. Salicylate ingestions are known to exhibit unusual toxicokinetics and absorption in overdose; however, this is the first case we are aware of that shows a return to toxic concentrations after apparent resolution of toxicity. Recrudescence of salicylate concentrations to a degree that would dictate reinstitution of therapy for overdose is unusual and may warrant prolonged
\end{abstract}

\section{Funding: none}

Poster presentation-9/2008 North American Congress of Clinical Toxicology meeting in Toronto, Canada

P. L. West $(\triangle) \cdot$ B. Z. Horowitz

Department of Emergency Medicine,

Oregon Health and Science University,

3181 SW Sam Jackson Park Road,

Portland, OR 97239, USA

e-mail: westp@ohsu.edu

P. L. West • B. Z. Horowitz

Oregon Poison Center,

Portland, OR, USA monitoring of serum salicylate concentrations in salsalate ingestions.

Keywords Overdose $\cdot$ Salicylsalicylic acid $\cdot$ Salicylates

\section{Background}

Salicylate exposures were reported to Poison Centers 19,613 times in 2007 with 14 deaths [1]. Once serum salicylate concentrations return to the therapeutic range after treatment in an overdose scenario, most management guidelines no longer advise monitoring serum concentrations $[2,3]$. We report a salsalate overdose where a patient with elevated serum salicylate concentrations was treated with sodium bicarbonate and activated charcoal, with decline of serum salicylate concentrations to subtherapeutic concentrations followed by a subsequent return to toxic concentrations necessitating reinstitution of therapy.

\section{Case Report}

A 31-year-old male with a history of depression, posttraumatic stress disorder, and prior suicide attempts was discovered at 7 am by his neighbors with decreased level of consciousness after a suicide note stating he was planning to kill himself with "anxiety and narcotic medications" was found. On the arrival of Emergency Medical Services (EMS), he was rousable, and stated he had tried to kill himself "last night" via medication overdose, but refused to give further information about the overdose. Thirty-six new and old pill bottles were found next to him, including acetaminophen (APAP), hydrocodone/APAP, hydroxyzine, ibuprofen, lorazepam, magnesium oxide, morphine, oxy- 
codone, paroxetine, ranitidine, salsalate, senna, temazepam, tramadol, venlafaxine, and zolpidem. There was no evidence of other salicylate-containing preparations among the medications that were brought with him.

He was transported to the emergency department by EMS, vomiting once en-route, with no pill fragments present in the vomitus. On arrival, he had a blood pressure of $162 / 92 \mathrm{mmHg}$, pulse of $100 \mathrm{bpm}$, respiratory rate of $14 / \mathrm{min}$, and oxygen saturation of $98 \%$ on room air, and a Glasgow Coma Scale of 14. He was initially sleepy, but rousable and told his physicians that he had ingested several pills, but would provide no other information. He had an otherwise normal physical examination, including normal, reactive pupils and the presence of bowel sounds. Laboratory values on presentation included a sodium of $144 \mathrm{mmol} / \mathrm{L}(136-145 \mathrm{mmol} / \mathrm{L})$, potassium of $4.1 \mathrm{mmol} / \mathrm{L}$ $(3.5-5.1 \mathrm{mmol} / \mathrm{L}), \mathrm{HCO}_{3}$ of $33 \mathrm{mmol} / \mathrm{L}(22-32 \mathrm{mmol} / \mathrm{L})$, chloride of $104 \mathrm{mmol} / \mathrm{L}(100-110 \mathrm{mmol} / \mathrm{L})$, BUN of $18 \mathrm{mg} / \mathrm{dL}(7-23 \mathrm{mg} / \mathrm{dL})$, creatinine of $1.2(0.7-1.3 \mathrm{mg} /$ $\mathrm{dL}$ ), and glucose of $125 \mathrm{mg} / \mathrm{dL}$ ( $70-115 \mathrm{mg} / \mathrm{dL})$. His serum salicylate concentration was $29.2 \mathrm{mg} / \mathrm{dL}$, acetaminophen concentration $<2 \mathrm{mcg} / \mathrm{mL}$, and ethanol $<10 \mathrm{mg} / \mathrm{dL}$. Urine drug screen by immunoassay on the Dimension RxL system was positive for benzodiazepines and cannabinoids, and negative for amphetamines, barbiturates, cocaine, methadone, opiates, phencyclidine, and propoxyphene. His initial arterial blood gas on room air showed $\mathrm{pH}$ of 7.34, $\mathrm{pCO}_{2}$ of $46 \mathrm{mmHg}$, and $\mathrm{pO}_{2}$ of $80 \mathrm{mmHg}$. His EKG revealed a narrow complex sinus rhythm with normal QRS and QTc intervals, and no evidence of ischemic changes. His clinical and laboratory assessment at this time was not felt to be consistent with pure salicylism, and he was admitted to the ICU for a polysubstance overdose. No charcoal was given in the ED for concerns about future airway deterioration.

On initial ICU evaluation approximately $3 \mathrm{~h}$ after presentation, his HR was 112 , BP was $154 / 63$, RR was 9, and oxygen saturation was $97 \%$ on room air. Subsequently, the patient's level of consciousness and respiratory rate decreased. An arterial blood gas immediately before intubation showed a $\mathrm{pH}$ of 7.31, a $\mathrm{pCO}_{2}$ of 48 , and a $\mathrm{pO}_{2}$ of 111 . He was intubated for an episode of apnea $5.5 \mathrm{~h}$ after presentation to the emergency department. Intravenous sodium bicarbonate $\left(\mathrm{NaHCO}_{3}\right)$ therapy was initiated with $150 \mathrm{mEq}$ (three ampules) $\mathrm{NaHCO}_{3}$ in $1 \mathrm{~L}$ of D5W running at $200 \mathrm{~mL} / \mathrm{h}$. Two doses of activated charcoal (the first a 100 -g dose followed by a 50 -g dose) were administered through a nasogastric tube (Fig. 1). Salicylate concentrations peaked at $55 \mathrm{mg} / \mathrm{dL}$ just over $8 \mathrm{~h}$ after presentation to the emergency department. During this peak, he had serial $\mathrm{pH}$ values between 7.37-7.45, urine $\mathrm{pH}$ was measured at 5.5 , serial potassium concentrations of $3.1-4.1 \mathrm{mmol} / \mathrm{L}$, and serial serum $\mathrm{HCO}_{3}$ concentrations varied from 25$33 \mathrm{mmol} / \mathrm{L}$. His serum salicylate concentrations declined (Fig. 1) and the $\mathrm{IV} \mathrm{NaHCO}_{3}$ therapy was stopped $26 \mathrm{~h}$ after presentation. He had two charcoal bowel movements between 36 and $41 \mathrm{~h}$ after his presentation. Thirty-eight hours after presentation, his serum salicylate concentration reached a nadir of $5.6 \mathrm{mg} / \mathrm{dL}$. The physician's order to obtain serum salicylates was not discontinued at this time, and his serum salicylate concentrations rose slowly. Fortynine hours after presentation, he was extubated; at this
Fig. 1 Salicylate concentration $(\mathrm{mg} / \mathrm{dL})$ from time of presentation (hours). Solid arrows denotes activated charcoal dose. Green bar denotes IV dosing of $\mathrm{NaHCO}_{3}$. Dotted arrow denotes time of extubation. $\mathrm{pH}_{a}$ is arterial $\mathrm{pH} . p H_{v}$ is venous $\mathrm{pH}$. $p H_{u}$ is urine $\mathrm{pH}$

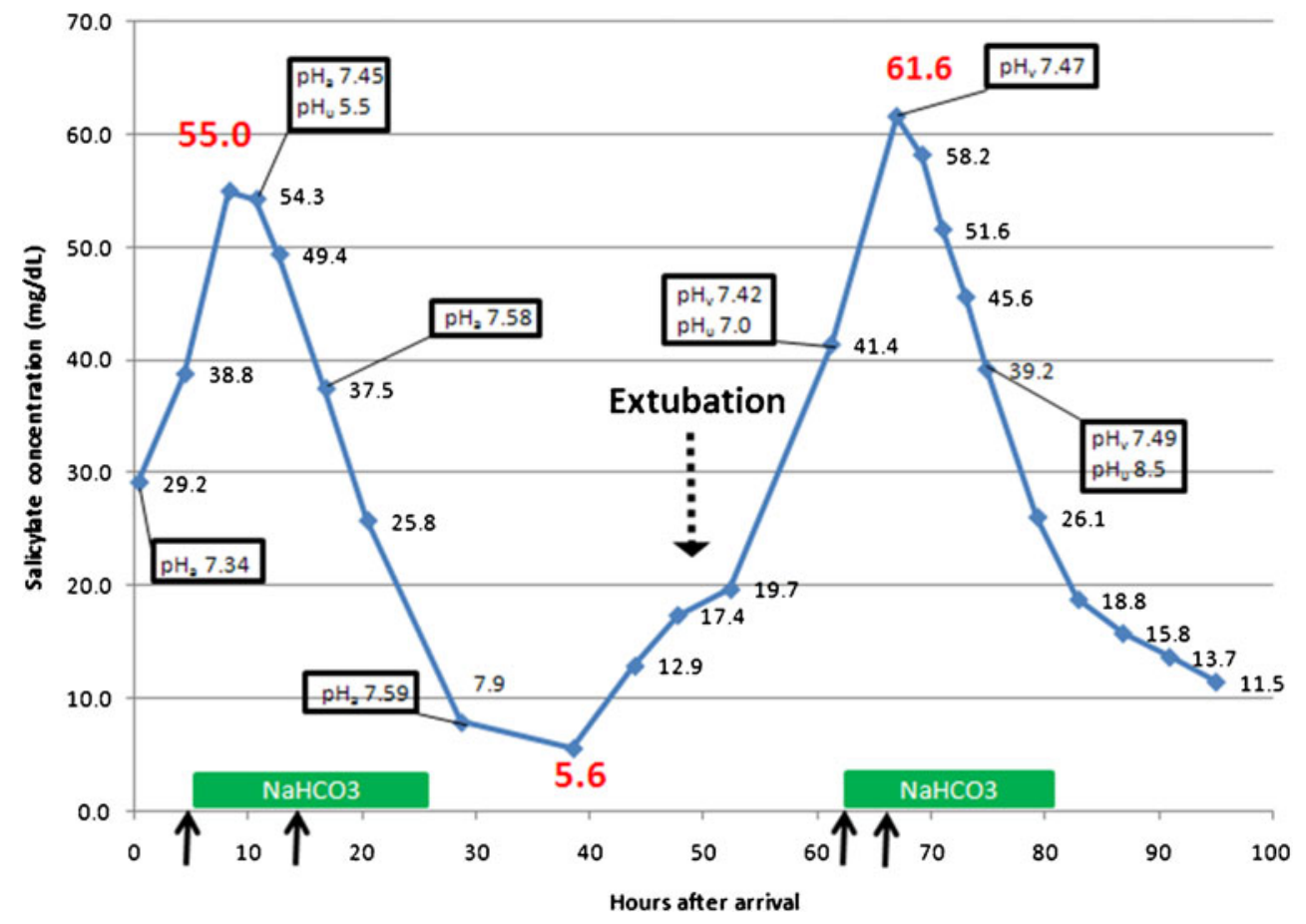


point, his serum salicylate concentration had already risen to $17.4 \mathrm{mg} / \mathrm{dL}$. His venous blood gas at this time showed a $\mathrm{pH}$ of 7.36 and a $\mathrm{pCO}_{2}$ of $46 \mathrm{mmHg}$.

After his extubation, during psychiatric interview, he was relatively certain that he had taken salsalate, hydroxyzine, and a benzodiazepine. He was kept on a psychiatric hold and under the supervision of a one-to-one sitter. During this period no salicylates were administered and he had no access to his home medications.

Continued monitoring of salicylate concentrations showed a continued rise (Fig. 1). The patient began to complain of tinnitus $61 \mathrm{~h}$ after presentation $(33 \mathrm{~h}$ after his level dropped to $7.9 \mathrm{mg} / \mathrm{dL}$ ), when his concentration reached $41.4 \mathrm{mg} / \mathrm{dL}$. Venous blood gas at this time revealed a $\mathrm{pH}$ of 7.42 and a $\mathrm{pCO}_{2}$ of $39 \mathrm{mmHg}$. His room was searched during the second elevation, and no evidence of surreptitious salicylate administration was discovered. He denied taking a second dose of salicylate. The IV $\mathrm{NaHCO}_{3}$ therapy was restarted at the previous dose and rate $62 \mathrm{~h}$ after presentation and he was given two more 50 -g doses of activated charcoal without cathartic. His salicylate concentrations peaked at $61.6 \mathrm{mg} / \mathrm{dL}$ at $67 \mathrm{~h}$ after his admission. During the second salicylate peak, his urine $\mathrm{pH}$ was 7.0 8.5 , his serum $\mathrm{pH}$ ranged from 7.36 to 7.50 on venous blood gas, his serum $\mathrm{HCO}_{3}$ ranged from $24-29 \mathrm{mmol} / \mathrm{L}$, and his potassium ranged from 3.5 to $3.8 \mathrm{mmol} / \mathrm{L}$. His salicylate concentration slowly returned to therapeutic concentrations. He was subsequently transferred to a psychiatric facility and remained asymptomatic.

\section{Discussion}

Salicylsalicyclic acid (SSA), or salsalate, is the salicylate ester of salicyclic acid (SA) (Figs. 2 and 3). Salsalate is an NSAID analog of aspirin that causes less GI bleeding and has fewer platelet effects [4,5]. Salsalate is minimally absorbed in the acidic $\mathrm{pH}$ of the stomach, but is much more rapidly liberated in the basic $\mathrm{pH}$ in the small intestine. Theoretically, the majority of absorption occurs in the small intestine, although there are no in vivo studies demonstrating this phenomenon [6]. Absorption is thought to occur

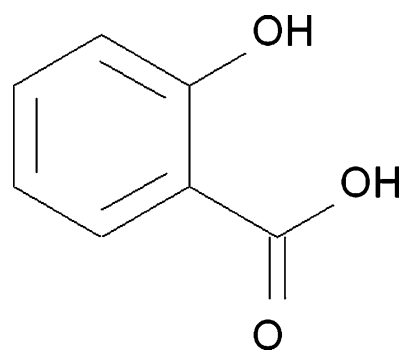

Fig. 2 Molecular structure of salicyclic acid

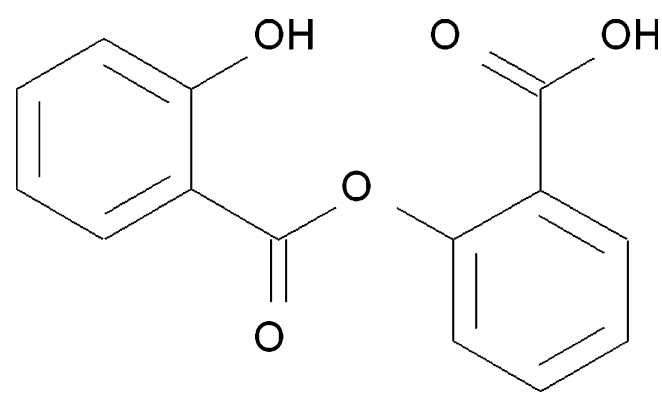

Fig. 3 Molecular structure of salsalate (salicylsalicyclic acid)

faster than enteric-coated aspirin, but slower than nonenteric-coated aspirin [5]. SSA is hydrolyzed by esterases to two molecules of SA in the small bowel prior to absorption and in the GI mucosa after absorption. A small percentage of the produced SA then undergoes first pass metabolism via the liver, thus decreasing the total amount of SA available compared to an equivalent dose of aspirin $[7,8]$. Metabolism is nearly complete, with less than $1 \%$ of SSA being excreted unchanged in the urine [7]. Mean peak SSA concentrations occur $1.5 \mathrm{~h}$ after therapeutic dosing and are undetectable in most patients $6 \mathrm{~h}$ after dosing, with a calculated plasma half life of $1.1 \mathrm{~h}$ [9]. SA concentrations typically peak 4-7 $\mathrm{h}$ after therapeutic SSA dosing [9]. With equivalent dosing of salsalate and aspirin, SA concentrations are higher during the first $2 \mathrm{~h}$ after aspirin dosing; however, after the first $2 \mathrm{~h}$, there is no significant difference in the concentration of SA in the blood [9]. Salsalate's effects in therapeutic dosing have been shown to be comparable to those of aspirin with similar blood SA concentrations after comparable therapeutic dosing $[4,10]$. This suggests that at least in therapeutic dosing, salsalate appears to behave like regular aspirin.

Unpredictable absorption is a well-known phenomenon in enteric-coated salicylate overdose. Enteric-coated aspirin are designed to be stable in the stomach's acidic environment and delay absorption until the pill has time to move through the GI tract. Upon reaching an environmental $\mathrm{pH}$ above 6.0, the coating dissolves and the salicylate is released, causing a delayed peak concentration and extended effect of the salicylate preparation [11]. This pharmacokinetic model is similar to the absorption model of salsalate, where minimal absorption occurs in the stomach, with subsequent increased absorption in the small intestine [6]. There can be some hydrolysis of SSA in the small bowel, as well, which could lead to formation of acetylsalicylate bezoar in the gut [9]. In enteric-coated salicylate overdose, peak serum concentrations have been delayed as long as $60 \mathrm{~h}$ after ingestion in one reported ingestion [12]. Other cases have reported delayed absorption, with undetectable initial salicylate concentrations 1 and $3 \mathrm{~h}$ after an entericcoated aspirin ingestion, followed by a rise to concerning concentrations [13]. Large overdoses of enteric-coated 
aspirin have been shown to lead to bezoar formation [11]. Salicylate bezoars have been proven by barium swallow and/or upper endoscopy in patients with abnormal and normal gastrointestinal motility and anatomy [14, 15]. Serum salicylate concentrations may not be elevated, even when a gastric bezoar as large as 66 salicylate tablets is proven to be present [14]. These unpredictable kinetics present in overdose require close monitoring of serum salicylate concentrations.

The clinical course of salsalate in overdose is not well described. Given the similar mechanism of absorption, it is possible that in overdose SSA moves from kinetics similar to non-enteric-coated aspirin and takes on characteristics of enteric-coated aspirin. The one published case of salsalate overdose we found describes a patient with significant presenting clinical symptoms of salicylism, but initial SA concentrations much lower than were expected for the degree of symptomatology [16]. This patient's serum salicylate concentrations ultimately reached $94 \mathrm{mg} / \mathrm{dL} 8 \mathrm{~h}$ after absorption, causing the authors to postulate that the circulating SSA caused similar symptoms to SA prior to hydrolysis [16].

One guideline for managing a salicylate overdose suggests that in overdose situations serum salicylate concentrations should be checked "until the patient is clinically improving and has a low salicylate concentration" [2]. While poison centers management recommendations vary, they usually suggest that once an elevated salicylate concentration has returned to therapeutic concentrations (either one or two measurements) after an overdose, bicarbonate therapy may be stopped, and no further therapy is indicated for a salicylate overdose. Unfortunately, these guidelines would have "cleared" this patient $33 \mathrm{~h}$ prior to the onset of his symptoms, which would have provided time for discharge or transfer to a psychiatric facility with few laboratory capabilities, with potentially disastrous results. We have found no literature to suggest other cases of delayed return of salicylate concentrations to toxic concentrations requiring therapy after completion of a successful treatment regimen.

There are several possibilities that could explain this phenomenon. The first possibility is that the patient took a second dose of salicylate in his room. We feel this is unlikely. The patient's salicylate concentration had risen to $17.4 \mathrm{mg} / \mathrm{dL}$ prior to his extubation. After extubation, he was observed with a one-to-one sitter while on a psychiatric hold, limiting his opportunity and access for self-administration. His room was searched, and no evidence of surreptitious salicylate administration was discovered. We feel this makes this unlikely to be the source of the delayed rise.

A change in renal excretion due to cessation of bicarbonate therapy is another possible explanation for the second rise. Assuming his salicylate was absorbed at a constant rate, a higher rate of excretion during sodium bicarbonate therapy could be expected, clearing the absorbed salicylate. Stopping the bicarbonate therapy would decrease excretion rate, but constant continued absorption, now greater than the excretion rate, could account for a delayed rise in serum salicylate concentration. This seems unlikely, as his urine $\mathrm{pH}$, an important determinant of salicylate excretion, remained relatively unchanged prior to and during the second rise, compared to the time of the nadir of his concentrations.

Another possibility is that the salsalate was initially completely absorbed as unhydrolyzed SSA, and elevated concentrations were not detected by the initial serum salicylate analysis. This seems unlikely as the patient was asymptomatic after extubation, with return of tinnitus as his salicylate concentrations rose. Persistent tinnitis would be expected with significant SSA toxicity.

The final possibility is that, given its lack of absorption in acidic environments, it is possible that decreased GI motility from the coingested medications (either anticholinergics or opioids) could have created an undigested pill collection or bezoar in the stomach or that the SSA was hydrolyzed in the small bowel to SA creating a SA bezoar. Such a bezoar that is not in a region of the gastrointestinal tract where it may be absorbed could be reflected by undetectable serum salicylate testing [14]. Once gut motility returned, and after the initial salicylate load was cleared, a second period of absorption and subsequent serum salicylate elevation may have occurred. The first bowel movement was approximately $2 \mathrm{~h}$ prior to the nadir of levels, which would be consistent with the time that in therapeutic dosing of SSA that it took for SA levels to begin to rise [9].

The incidence of the described phenomenon is unknown. It is possible that this was an unusual occurrence solely due to the toxicokinetics of salsalate in overdose. We find the return of gastrointestinal motility as his co-ingestant's effects subsided, coupled with possible bezoar formation, to be the most compelling of the discussed etiologies to explain this phenomenon. A more concerning question is whether this is a more frequently occurring event than is recognized in general salicylate overdoses, and one that current monitoring protocols are missing. We have changed our protocols at our poison center, by recommending checking salicylate concentrations 6 and $12 \mathrm{~h}$ after bicarbonate therapy has stopped in order to ensure that we are not missing more of these cases. The prospective evaluation of this phenomenon is a crucial area of future research.

\section{Conclusion}

We report an unusual case of salsalate ingestion with resolution of symptoms and salicylate concentrations to non-toxic values, with a subsequent, unexpected elevation to toxic concentrations requiring reinstitution of therapy. Clinicians should be wary of atypical kinetics in salsalate 
ingestions and possibly other salicylate formulations and should consider prolonged monitoring of salicylate concentrations in these circumstances.

\section{References}

1. Bronstein AC, Spyker DA, Cantilena LR, Green J, Rumack BH, Heard SE (2007) Annual Report of the American Association of Poison Control Centers National Poison Center Database (NPDS). Clin Toxicol 45:815-917

2. Flomenbaum N (2006) Salicylates. In: Flomenbaum H, Goldfrank L, Hoffman R et al (eds) Goldfrank's Toxicologic Emergencies, 8th edn. McGraw-Hill, New York, pp 550-564

3. Salicylate, Ellenhorn MJ, Schonwald S, Ordog F, Wasserberger J (1997) Ellenhorn's medical toxicology: diagnosis and treatment of human poisoning, 2nd edn. Williams \& Wilkins, Baltimore, pp 210-223

4. Linyanage SP, Tambar PK (1978) Comparative study of salsalate and aspirin in osteoarthrosis of the hip or knee. Curr Med Res Opin 5(6):450-453

5. Mielants H, Veys EM, Verbruggen G, Schelstraete K (1981) Comparison of serum salicylate levels and gastro-intestinal blood loss between salsalate (Disalcid) and other forms of salicylates. Scand J Rheumatol 10(3):169-173

6. Hanzlik PJ, Presho NE (1926) The salicylates XV. Liberation of salicyl from and excretion of salicylsalicylate. J Pharmacol Exp Ther 26:61-70
7. Dromgoole SH, Cassell S, Furst DD, Paulus HE (1993) Availability of salicylate from salsalate and aspirin. Clin Pharmacol Ther 34(4):539-545

8. Salsalate (2007) In: Sweetman SC, Blake PS, McGlashan PM, Neathercoat GC, Parsons AV (eds) Martindale: the complete drug reference, 35th edn. Pharmaceutical, London, p 106

9. Harrison LI, Funk ML, Re ON, Ober RE (1981) Absorption biotransformation, and pharmacokinetics of salicylsalicyclic acid in humans. J Clin Pharmacol 21:401-404

10. McEvoy G, Snow E, Kester L, Litvak K, Miller J et al. (2006) eds. American Society of Health System Pharmacists Drug Information, 2006. The American Society of Health System Pharmacists Inc 2015, Bethesda

11. Bogacz K, Caldron P (1987) Enteric-coated aspirin bezoar: elevation of serum salicylate level by barium study. Am J Med 83:783-786

12. Todd PJ, Sills JA, Harris F, Cowen JM (1981) Problems with overdoses of sustained-release aspirin. Lancet 1(8223):777

13. Wortzman D, Grunfeld A (1987) Delayed absorption following enteric-coated aspirin overdose. Ann Emerg Med 16:434 436

14. Sogge MR, Griffith JI, Sinar DR, Mayles GR (1977) Lavage to remove enteric-coated aspirin and gastric outlet obstruction. Ann Intern Med 87:721

15. Salhanick S, Levy D, Burns M (2002) Aspirin bezoar proven by upper endoscopy (abstract). J Toxicol Clin Toxicol 40:688

16. Spontak SF, Spontan MH, Spadafora MP (1994) Salsalate intoxication and ramifications of utilizing non-specific analytical methods in estimating quantitative blood concentrations. J Anal Toxicol 18:229-231 